\title{
A cross-sectional study of pre-service teachers' views about disability and attitudes towards inclusive education
}

Nketsia, William $₫$

University of Jyväskylä, Jyväskylä, Finland (william.w.nketsia@jyu.fi)

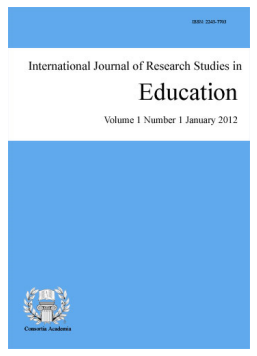

Accepted: 20 September 2016

ISSN: 2243-7703 Online ISSN: 2243-7711

OPEN ACCESS

\section{Abstract}

Teachers' attitudes towards students with disabilities and special educational needs (SEN) and their inclusion in regular education classrooms have been internationally identified as a key factor in the implementation of inclusive education. In this study, 501 participants representing a cross-section of pre-service teachers from three public colleges of education in Ghana were surveyed about their views regarding disability, level of discomfort interacting with people with disabilities and attitudes towards inclusive education. The results indicate that the pre-service teachers understood disability as an interaction between biological and environmental factors and felt comfortable interacting with people with disabilities. However, their attitudes towards inclusive education were imperceptibly positive, with some being predisposed to cultural and religious beliefs about disability. The results are discussed in relation to the impact of background variables and the range of factors that can improve pre-service teachers' attitudes towards inclusive education.

Keywords: pre-service teachers' attitudes; cultural and religious beliefs; conceptualization of disability; level of discomfort; inclusive education; Ghana 


\section{A cross-sectional study of pre-service teachers' views about disability and attitudes towards inclusive education}

\section{Introduction}

It is estimated that about $80 \%$ of the world's population with some form of disability live in the global south (World Health Organization [WHO] \& World Bank, 2011). The WHO estimates on the basis of the World Health Survey that between 2001 and 2004, the disability rate in Ghana was 12.8\% (WHO \& World Bank, 2011) of the entire population, which is estimated at around 27 million (Central Intelligence Agency, 2015). It is also estimated that $98 \%$ of children with disabilities in the global south do not attend school (UNICEF, 2015). According to a new report (UNESCO-UIS, 2015), between 10\% and 19.9\% (0.5 million) of children of primary school age in Ghana are out of school, making Ghana part of the region with the highest out-of-school rate. About $25 \%$ of out-of-school children aged six to 14 have at least one known form of disability, and the majority of them are excluded from school or have the lowest literacy levels (Ametepee \& Anastasiou, 2015; Ministry of Education, 2015). The conceptualisation of disability in policy documents has considerable influence on the estimates of disability prevalence (UNICEF, 2013) and the kinds of educational policy provisions and programmes that are available for persons with disabilities (Avoke, 2001, 2002; Lindsay, 2003). This paper begins with a description of some models of disability and inclusive education and the relevant policy in Ghana. It then discusses teachers' attitudes towards disability and inclusion and teacher preparation for basic education in Ghana before delving into the method used as well as the results obtained; a discussion and conclusion.

\subsection{Conceptualizing disability in Ghana}

Several conceptual models have been developed to define disability. For the purpose of this paper, the individual (or medical) view, the social model view and the WHO's International Classification of Functioning, Disability and Health (ICF) model will be discussed. The individual or medical model views disability as a personal tragedy caused by impairments, health conditions, disease or trauma that must be prevented or treated by professionals (Oliver, 2013; Thomas, 2008). Consequently, this view locates disability, learning problems and deficiency within children with disability rather than in curricula, school cultures and teaching and learning approaches (Booth \& Dyssegaard, 2008; Purdue et al., 2009). It leads teachers to believe that children identified with disability or SEN are different or special and must therefore receive special or segregated education (Florian \& Rouse, 2009; Thomas, 2008).

Conversely, the social model views disability as a socially-created problem caused entirely by oppressive social barriers (structural and attitudinal) that people with impairments (physical, intellectual and sensory) come up against in society. This breaks the causal link between impairment and disability and has the potential to improve the lives of disabled people by advancing the common individual interests of disabled people, their social and political equality and their full civil rights (Oliver, 2013; Thomas, 2008).

Although these two models are partially valid, they only narrowly describe disability. Social model views fail to recognise the role of impairments in disabled people's lives while the medical model fails to take into account social barriers to functioning and participation (Thomas, 2008; UNICEF, 2013; WHO, 2001). The current ICF/WHO or bio-psycho-social model sought to address the limitations of these two models by conceptualising disability as a dynamic interaction between an individual (with a health condition or impairment) and his/her contextual factors (environmental and personal) (WHO, 2001, 2013). This does not attribute disability entirely to persons with impairments and acknowledges the interaction between students, the learning environment and the curriculum (McGhie-Richmond \& Sung, 2013). It has been broadly endorsed by the United Nations and other international organisations (United Nations, 2006; UNICEF, 2013; WHO \& World Bank, 2011). Consequently, to address the civil, cultural, political, social and economic rights of persons with 
disabilities, disability is increasingly understood as a human rights issue following the adoption of the United Nations Convention on the Rights of Persons with Disabilities (United Nations, 2006).

Although the current policy on inclusive education in Ghana has adopted the WHO's model (Ministry of Education, 2015), however, the individual or medical model has been found to be the most dominant in many policy documents relating to inclusive education (Anthony, 2011; Lamptey et al., 2015), thus resulting in limited educational opportunities for children with disabilities. In Ghana, residential special schools have been established for students with specific disabilities such as visual and hearing impairments and intellectual and developmental disabilities (Anthony, 2011; Avoke, 2001; Ministry of Education, 2015).

Groce (1999) has argued that different cultures have different interpretations and complex system of beliefs and practices concerning disability. Apace with the dominance of the individual model in Ghana, religious (or magical) (Avoke, 2002) and cultural (or traditionalist) models (Agbenyega, 2003; Anthony, 2011) have been found to influence people to think that disabilities are caused by an evil placed on an individual from the gods, devil, evil spirits, ghosts and powers of sorcery as a result of offences this individual has committed. They believe that disability is caused by witchcraft, evil spirits and ghosts or a curse or punishment from gods, juju or deity for one's wrongs (Agbenyega, 2003; Avoke, 2002; Botts \& Owusu, 2013). These beliefs are dominant in sub-Saharan African countries (see example Anthony, 2011; Dart, 2006; Gaad, 2004). Also, studies from countries in Asian and Middle East regions such as Israel (Florian \& Katz, 1983), United Arab Emirates (Gaad, 2004), and Nepal (Dhungana, 2006) have indicated that disability is often portrayed as something fearful and usually understood as retribution for sinful deeds, curse for the handicapped child and his family or caused by demons or God's will. They believe disability could be inherited by children and that disability brings bad luck in family and religious ceremonies.

\subsection{The concept of inclusive education and the related policy in Ghana}

Inclusive education is based on the social model and demands the adaptation of the existing regular education school system to include everyone, celebrate difference, support learning, respond to individual needs and combat discriminatory attitudes (UNESCO, 2009, 1994). Adopted at the World Conference on Special Needs Education in Salamanca, Spain, 7-8 June 1994, inclusive education is described as the education of students with SEN and disabilities, with their unique characteristics, interests, abilities and learning needs, in regular schools capable of meeting their needs within a child-centred pedagogy (UNESCO, 1994).

Recently, Ghana has successfully launched a national policy framework on inclusive education to address the challenges faced by children with SEN (Ministry of Education, 2015). The policy directive seeks inclusive education for all persons with mild and severe SEN at all levels of education. It entreats regular schools to provide education for all children, regardless of their physical, intellectual, social, emotional, linguistic or other disabilities. Ghana has made major progress towards the implementation of inclusive education by expanding the Inclusive Education Pilot Programme from 29 districts in seven regions in 2011 to 46 districts in all of its ten regions today (Ministry of Education, 2015).

However, progress regarding the implementation of inclusive education in Ghana has been very slow due to barriers such as inaccessible curricula, inadequate assessment facilities, architectural barriers, curriculum inflexibility, lack of teaching and learning materials, inadequate supply of exercise books, lack of textbooks/syllabus, a high and growing prevalence of untrained teachers, large class sizes, inadequate teacher-centred methodologies and inadequate teacher training (Agbenyega, 2007; Ametepee \& Anastasiou, 2015; Kuyini \& Mangope, 2011; Singal, Salifu, Iddrisu, Casely-Hayford, \& Lundebye, 2015). Similar challenges are affecting the implementation of inclusive education in India (Pacha, 2012), United Arab Emirates and Jordan (Alghazo, Dodeen, \& Algaryyouti, 2003; Nisreen, 2013), Bangladesh (Malak, 2013) and Egypt (El-Ashry, 2009; Nisreen, 2013).

Another barrier facing the Government of Ghana in the development of educational and social inclusion for 
those with disabilities are the dominant religious/magical or cultural beliefs about disability that engender negative attitudes and prejudices towards people with disabilities (Agbenyega, 2003, 2007; Anthony, 2011; Avoke, 2002; Ghana Education Service, 2004; Naami \& Hayashi, 2012). Consequently, in Ghana children with disabilities are often killed or isolated in rooms, hidden from public view by their families or kept in institutions secluded from mainstream society, such as religious camps and residential special schools. These beliefs have resulted in the derogatory labelling, stigmatisation, discrimination and social exclusion of persons with disabilities in all aspects of life, human rights abuses and the segregation of children with disabilities into residential special schools (Agbenyega, 2003, 2007; Anthony, 2011; Avoke, 2001, 2002; Botts \& Owusu, 2013; Dart, 2006; Kassah, Kassah, \& Agbota, 2012; UNESCO, 1988). Those in regular schools are mistreated by their teachers and other students; they are labelled as stubborn, lazy, wayward, stupid, idiotic and blockheaded in classrooms characterised by excessive corporal punishment such as caning, knocking, ears pulling and pinching (Agbenyega, 2003).

Similarly, studies from Israel (Florian \& Katz, 1983), Bangladesh (Malak, 2013), Nepal (Dhungana, 2006), India (Pacha, 2012), United Arab Emirates and Jordan (Alghazo et al., 2003; Gaad, 2004) and other cross-cultural studies (Groce, 1999) have shown that these cultural and ethnic beliefs about causes of disabilities appear to influence negative attitudes towards the disabled and marginalized minority groups and their educational and social inclusion. The cultural understanding of disability places enormous limitation on the lives of individuals with disability much more than their specific type of impairments (Groce, 1999). Consequently, Ghana has adopted inclusive education as a strategy to tackle these discriminatory attitudes that result in the exclusion of students with disabilities from teaching and learning processes in the classroom and to include those who are out of school due to SEN requirements (Ministry of Education, 2015).

\subsection{Teachers' attitudes towards disability and inclusion}

It is globally recognised that teachers' attitudes towards students with disability and SEN and their inclusion in regular education classrooms are a key factor in the implementation of inclusive education. Challenging teachers' negative attitudes towards persons with disabilities and their educational and social inclusion is the first step and most important factor towards creating more accessible environments for persons with disabilities (Avramidis \& Norwich, 2002; Campbell, Gilmore, \& Cuskelly, 2003; Chhabra, Srivastava, \& Srivastava, 2010; Parasuram, 2006; WHO \& World Bank, 2011). There are mixed results regarding teachers' attitudes towards the inclusion of students with SEN and disabilities into regular classrooms in both developed and developing countries.

For instance, some results have shown that the majority of teachers hold neutral or negative attitudes towards students with SEN and disabilities and their inclusion in regular primary education (Chhabra et al., 2010; De Boer, Pijl, \& Minnaert, 2011; Hudson, Graham, \& Warner, 1979; Parasuram, 2006) while others have found evidence of positive teacher attitudes (Avramidis \& Norwich, 2002; Scruggs \& Mastropieri, 1996). Similarly, some studies have found positive attitudes among pre-service teachers towards disability (Forlin \& Chambers, 2011; Haimour, 2012) and inclusive education (Lambe \& Bones, 2006; Muwana, 2012); others have found negative attitudes towards disability (Alghazo et al., 2003) and inclusive education (EL-Ashry, 2009; Kuyini \& Mangope, 2011; Malak, 2013).

Both pre- and in-service teachers have raised several concerns about inclusive education programmes. These concerns, identified as factors impacting teachers' attitudes towards inclusive education, include insufficient time, inadequate teacher preparation, lack of skills, lack of resources, lack of administrative support services, lack of knowledge about disabilities, high workloads, inflexible curricula, large class sizes and the nature of the disability (Avramidis \& Norwich, 2002; Chhabra et al., 2010; De Boer et al., 2011; Hudson et al., 1979; Lambe \& Bones, 2006; Scruggs \& Mastropieri, 1996).

Further to the above educational environment-related variables, child-related variables (such as the nature of 
disabilities) and teacher-related variables (such as gender, previous teaching experience, experience of contact with persons with disabilities, training and teachers' beliefs) have also been found to impact significantly on teachers' attitudes (Avramidis \& Norwich, 2002). Some studies have shown that pre-service teachers were more positive about including students with mild support needs, such as those who have difficulty expressing their thoughts verbally (Forlin \& Chambers, 2011; Kuyini \& Mangope, 2011), students with learning disabilities, hearing and health impairments (McCray \& McHatton, 2011) and physical disabilities (Muwana, 2012). Studies from Ghana (Kuyini \& Mangope, 2011), United Arab Emirates (Gaad, 2004; Nisreen, 2013) and Egypt (El-Ashry, 2009) have affirmed that teachers are more inclined to include students with minor and mild disabilities than students with more severe disabilities.

Regarding teacher-related variables, some studies have shown that female teachers were more positive towards students with disabilities (Haimour, 2012) and inclusion (Parasuram, 2006). Conversely, Forlin, Loreman, Sharma and Earle (2009) found male pre-service teachers to be more positive about inclusion. Others have shown that teachers with prior teaching experience with children who have disabilities (Chhabra et al., 2010; Forlin et al., 2009; Nisreen, 2013) demonstrate more positive attitudes and less discomfort. Furthermore, some educational programme specialisations positively influence pre-service teachers' attitudes towards students with disabilities and inclusion, for example, special education (Haimour, 2012) and education and humanities (Alghazo et al., 2003). Forlin and Chambers (2011) also observed that previous training, the level of experience of educating students with disabilities or achievement of higher qualifications do not influence teachers' overall attitudes or concerns about inclusion. Conversely, increased contact with persons with disabilities has been found to explain positive changes in scores on comfort levels (Carroll, Forlin, \& Jobling, 2003; Sharma et al., 2008). Pre-service teachers with a family member or close friend with a disability exhibit more positive attitudes towards students with disabilities (Haimour, 2012) and inclusion (Dart, 2006; Parasuram, 2006) and fewer concerns about the inclusion of students with disabilities into regular classes (Chhabra et al., 2010; Forlin et al., 2009; Malak, 2013).

Above all, pre-service teacher education has been found to significantly promote teachers' knowledge about disabilities, their attitudes towards disability and inclusive education and their confidence and competence in teaching children with diverse educational needs (Forlin \& Chambers, 2011; Hudson et al., 1979; McCray \& McHatton, 2011). Studies have shown that after taking a course in special education, pre-service teachers became more positive, felt more comfortable interacting with people with disabilities and had fewer concerns about implementing inclusive education in classrooms (Campbell et al., 2003; Carroll et al., 2003; Dart, 2006; Sharma et al., 2008; Forlin et al., 2009). Some of these pre-service special education courses have been effective because of the inclusion of elements such as structured fieldwork experiences and interactions with people with disabilities (Campbell et al., 2003; Carroll et al., 2003; Hudson et al., 1979) as well as an emphasis on inclusive instructional strategies and the incorporation of assignments that require students to reflect on their own practices (Sharma et al., 2008).

\subsection{Initial teacher education for basic education in Ghana}

Initial teacher education for basic education in Ghana is a three-year diploma programme in basic education offered in all the 38 public and three private colleges of education. Basic education is made up of kindergarten, primary school and junior high school. The current requirement into colleges of education is the Senior High School Certificate Examination. Pre-service teachers spend the first two years in college undertaking coursework, school attachments and on-campus teaching practice. The third year provides an opportunity for them to spend time in real classroom situations to study and learn to teach.

Special education content knowledge and skills have been introduced into the regular pre-service training curriculum since late 1980 s to provide regular classroom teachers with skills to identify children with SEN and disabilities and to combat the negative attitudes of teachers regarding integration (UNESCO, 1988). All pre-service teachers currently undertake a two-credit course in special education at the end of their second year. 
Nketsia, W.

At the time of the data collection, the second- and third-year pre-service teachers had completed the SEN course.

Most studies on inclusive education in Ghana have focused on in-service regular classroom teachers' and principals' attitudes, knowledge and concerns about inclusive education (Agbenyega, 2007; Ocloo \& Subbey, 2008) as well as university students' attitudes towards disability (Naami \& Hayashi, 2012). One study on pre-service teachers' attitudes and concerns about inclusive education in Ghana found imperceptibly positive attitudes among pre-service teachers (Kuyini \& Mangope, 2011). This study further found that training in special/inclusive education was the only background variable relating to pre-service teachers that significantly improved their attitudes. Moreover, they were most concerned about lack of resources, workload and their own knowledge and skills for the implementation of inclusive education.

Previous studies have noted that prejudiced perceptions and negative attitudes towards persons with special needs and disabilities resulting from religious and cultural beliefs about disability could challenge the educational and social inclusion of people with disabilities (Agbenyega, 2003, 2007; Anthony, 2011; Avoke, 2002; Botts \& Owusu, 2013; Ghana Education Service, 2004). However, despite the increased interest in the implementation of inclusive education in Ghana, it is still not known the views and opinions pre-service teachers about these cultural and religious beliefs, their actual understanding of disability, their level of discomfort interacting with people with disabilities and the effectiveness of the special education course in addressing these issues.

\section{Research objectives}

A survey research approach was adopted to determine pre-service teachers':

Views and opinions regarding the cultural and religious beliefs about disability,

$>$ Views of disability,

$>\quad$ Level of discomfort interacting with people with disabilities, and

$>$ Attitudes towards inclusive education.

The effects of the independent variables on cultural and religious beliefs, understanding of disability, level of discomfort interacting with people with disabilities and attitudes towards inclusion were also determined.

\subsection{Method}

Participants - The study comprised 501 participants representing a cross-section of pre-service teachers at different educational levels (i.e. first year, second year and third year) from three of the 38 public colleges of education in Ghana. The three colleges were selected on the basis of proximity and ease of access. The mean age of the participants was 23.81 ( $\mathrm{SD}=2.35)$. Table 1 presents the demographic characteristics of the participants that might explain the variance of the dependent variables.

\section{Table 1}

Demographic characteristics of participants

\begin{tabular}{lllll}
\hline \multicolumn{1}{c}{ Characteristics } & $n$ & $\%$ & $M$ & $S D$ \\
\hline Gender & & & & \\
$\quad$ Male & 326 & 67 & 1.33 & .47 \\
$\quad$ Female & 164 & 33 & & \\
College of Education & & & & \\
College A & 226 & 45 & & \\
College B & 129 & 26 & 1.84 & .85 \\
College C & 146 & 29 & & \\
\hline
\end{tabular}


A cross-sectional study of pre-service teachers' views about disability and attitudes towards inclusive education

Table 1 ... continued

\begin{tabular}{lllll}
\hline \multicolumn{1}{c}{ Characteristics } & $n$ & $\%$ & $M$ & $S D$ \\
\hline Year & & & & \\
$\quad$ First year & 204 & 41 & & .80 \\
$\quad$ Second year & 169 & 34 & 1.85 & \\
$\quad$ Third year & 128 & 26 & & \\
Subject specialization & & & & \\
$\quad$ Math/science & 143 & 37 & & \\
$\quad$ Science/technical & 52 & 13 & & \\
$\quad$ General arts & 73 & 19 & 2.67 & \\
$\quad$ Social studies & 37 & 10 & & \\
$\quad$ Vocational studies & 86 & 22 & & \\
Completion of SEN course & & & & \\
$\quad$ Yes & 291 & 59 & & \\
$\quad$ Not yet & 201 & 41 & 1.41 & \\
Previous teaching experience & & & & \\
$\quad$ None & 212 & 43 & & \\
$\quad$ Some & 279 & 57 & 1.57 & .50 \\
Friends/classmates with disabilities & & & & \\
$\quad$ Yes & 229 & 46 & & \\
$\quad$ No & 266 & 54 & 0.46 & .50 \\
\hline
\end{tabular}

Procedure - Ethical approval was obtained from the University of Jyvaskyla and all the principals of the colleges of education involved in the study as a means of gaining genuine consent from respondents. These were in line with the ethical standards of the National Advisory Board on Research Ethics in Finland (2009). The main aim of the research was explained to the participants, and anonymity was assured. The pre-service teachers who voluntarily collected the questionnaires agreed to participate in the study. Each cohort in each college of education comprised nearly 300 pre-service teachers. To ensure a good response rate, 100 questionnaires were distributed to each educational level in each college except one educational level in one of the colleges, which received 150 survey forms due to its higher numbers. Out of the 950 survey questionnaires distributed, 501 were completed and returned for analysis, representing a return rate of $53 \%$.

\subsection{Measures}

Views on religious/cultural beliefs regarding causes of disability - Using a Likert scale, the participants were asked to indicate the extent to which traditional Ghanaian religious and cultural beliefs about the causes of disability were endorsed within their cultures as well as their agreement with these beliefs (ACB). The contents of the items are presented in Table 2. The item concerning their agreement was measured using a Likert scale from 1 to 5, including a neutral midpoint, with 1 indicating 'strongly disagree' and 5 indicating 'strongly agree'.

Level of discomfort interacting with people with disabilities - In the next part, a 4-item scale was used to measure the level of discomfort interacting with people with disabilities (LD). Two of these statements were originally designed by Gething and Wheeler (1992) 'The Interaction with Disabled Persons Scale', which addressed reactions suggesting discomfort interacting with people with disabilities, and appeared to demonstrate greater internal consistency (see e.g. Iacono et al., 2009; Sharma et al., 2008). These items were: 'I do not feel comfortable around people with disabilities' and 'I am afraid to look at a person with a disability straight in the face'. The other two statements were self-developed based on how people feel getting closer to people with disabilities in Africa (Botts \& Owusu, 2013; Dart, 2006; Kassah et al., 2012) and Asian and Middle East countries (Dhungana, 2006; Gaad, 2004). These items were: 'I find it difficult to relate with students with disabilities and special needs' and 'Disabilities can be transmitted by bodily contact'. All items were measured using a Likert scale from 1 to 5, with a neutral midpoint, with 1 indicating 'strongly disagree' and 5 indicating 'strongly agree'. The reliability of the scale was satisfactory with $\alpha=.73$.

Pre-service teachers' views about disability - The next part measured the construct of 'Pre-Service Teachers' 
Views about Disability' (VD). Six items were self-developed: 'To what extent do you agree that disabilities are caused by maternal exposure to drugs, x-rays and radiation?' 'To what extent do you agree that disabilities are caused by maternal malnutrition?' 'To what extent do you agree that disabilities can be caused by maternal diseases?' 'To what extent do you agree that disabilities can be caused during child birth?' 'To what extent do you agree that the home and school environment can make a child disabled? and 'To what extent do you agree that disabilities are caused by chromosomal or genetic abnormalities?' The items were measured using a Likert scale from 1 to 5, with a neutral midpoint, with 1 indicating 'strongly disagree' and 5 indicating 'strongly agree'. The reliability of the scale was satisfactory with $\alpha=.68$. An exploratory factor analysis of the six items yielded a unidimensional scale with $41.32 \%$ of the total variance explained. The Kaiser-Meyer-Olkin measure of sampling adequacy of .75 and Bartlett's test of sphericity were also highly significant: $\mathrm{x}^{2}(15)=491.587, p=.00$.

Pre-service teachers' attitudes towards inclusive education - The last section measured 'Pre-Service Teachers' Attitude towards Inclusive Education (PTAIES)'. The original scale was designed by EL-Ashry (2009) and consisted of 33 items drawn from previous studies to measure constructs such as benefits of inclusion, inclusive classroom management, ability to teach students with disabilities, special versus inclusive education and placements and perspectives towards teaching students with specific types of disabilities. This attitude scale was adopted in this study because of its cultural relevance to African contexts and its use for pre-service teachers in Egypt (EL-Ashry, 2009) and Zambia (Muwana, 2012). To ensure greater data reliability, the categories of SEN/disabilities, as stated in the special education curriculum of the colleges of education in Ghana, were used instead of those adopted in previous studies. On the basis of reliability and correlation analysis, 24 original items were removed from the scale because their item-total correlations were lower than .25 . The scoring of five items on the short version containing 19 items (i.e. 7, 8, 9, 10 and 12) was reversed, yielding a reliability of $\alpha=.70$.

The resulting data was entered into the IBM SPSS Statistics Program 22 and was analysed using simple frequencies, percentages, correlations, independent-samples t-tests and one-way between-groups analyses of variance.

\section{Results}

\subsection{Views on cultural and religious beliefs}

The participants' responses presented in Table 2 show that the culture of the majority of pre-service teachers endorsed some of the traditional Ghanaian cultural and religious beliefs about the causes of disability to some or very little extent. With regard to their agreement with cultural and religious beliefs about the causes of disability, the results show that nearly half of the participants (49\%) did not agree with the religious/magical and cultural beliefs; $25 \%$ agreed; and $26 \%$ were undecided. The overall mean score on the scale was $2.57(S D=1.20)$. Comparisons among the independent variables indicated that College $\mathrm{C}$ had the highest score $(M=2.84)$, followed by College A $(M=2.54)$ and College B $(M=2.33)$. The mean score for College $\mathrm{C}$ was significantly higher than that of colleges A and B according to post-hoc comparisons using the Tukey HSD test $F(2,493)=$ $6.57, p=.00$. However, the results did not indicate any statistically significant difference between the groups in relation to the other background variables.

\subsection{Views about disability}

The mean score for biological factors in causing disabilities $(M=4.25)$ was significantly higher than that pertaining to environmental factors $(M=3.55), t(498)=148.52, p=.00$. The first-year participants recorded the highest score for biological factors $(M=4.29)$, followed by the second-year participants $(M=4.28)$, with the third-year respondents $(M=4.12)$ scoring significantly lower according to post-hoc comparisons using the Tukey HSD test: $F(2,496)=3.55, \mathrm{p}=.03$. 
A cross-sectional study of pre-service teachers' views about disability and attitudes towards inclusive education

The total analysis of all 501 respondents on all the items of the VD scale indicated an overall mean of 4.13 $(S D=.62)$. The male pre-service teachers recorded higher mean scores $(M=4.20)$ than their female counterparts $(M=3.99), t(264.74)=3.28, p=.00$. The first-year pre-service teachers also reported the highest score $(M=$ 4.18), followed by the second-year participants $(M=4.17)$, while the third-year respondents scored $(M=3.99)$ significantly lower than the first- and second-year participants according to post-hoc comparisons using the Tukey HSD test $F(2,496)=4.23, p=.02$.

With regard to the level of discomfort interacting with people with disabilities, the total analysis of all 501 respondents indicated an overall mean of $1.97(S D=.82)$. No significant differences were found when all the independent variables were compared.

Table 2

Participants' $(N=501)$ responses to questions on cultural beliefs

\begin{tabular}{|c|c|c|c|c|c|c|}
\hline Cultural beliefs & $\begin{array}{c}\text { Very large } \\
\text { extent }\end{array}$ & $\begin{array}{l}\text { Large } \\
\text { extent }\end{array}$ & $\begin{array}{l}\text { Don't } \\
\text { know }\end{array}$ & $\begin{array}{c}\text { To some } \\
\text { extent }\end{array}$ & $\begin{array}{l}\text { Only very } \\
\text { little }\end{array}$ & Sum $\%$ \\
\hline $\begin{array}{l}\text { My CULTURE believes that } \\
\text { disabilities are caused by sorcery, } \\
\text { witchcraft or the devil? }\end{array}$ & 7 & 12 & 10 & 41 & 30 & $100 \%$ \\
\hline $\begin{array}{l}\text { My CULTURE believes that } \\
\text { children are born with disabilities } \\
\text { because their parents committed } \\
\text { offences against God, gods or } \\
\text { ancestral spirits? }\end{array}$ & 9 & 13 & 16 & 29 & 33 & $100 \%$ \\
\hline ACRB scale & $\begin{array}{l}\text { Strongly } \\
\text { Agree }\end{array}$ & Agree & Neutral & Disagree & $\begin{array}{l}\text { Strongly } \\
\text { Disagree }\end{array}$ & Sum $\%$ \\
\hline $\begin{array}{l}\text { How much do you agree with the } \\
\text { CULTURAL beliefs? }\end{array}$ & 5 & 20 & 26 & 25 & 24 & $100 \%$ \\
\hline
\end{tabular}

\subsection{Attitudes towards inclusive education}

The total analysis of all 501 respondents on all the PTAIES items indicated an overall mean of 3.35 (SD $=.46)$. College $\mathrm{C}$ had the highest score $(M=3.45)$, followed by college $\mathrm{B}(M=3.34)$. College A scored $(M=$ 3.29) significantly lower than College $C$ according to post-hoc comparisons using the Tukey HSD test $F(2,496)$ $=5.03, p=.01$. However, the results did not indicate any statistically significant difference between the groups regarding the other background variables. The participants expressed the most positive attitudes towards educating students with physical disabilities $(M=3.84)$ and behavioural problems $(M=3.56)$ in general education classrooms and the least positive attitudes towards those with hearing $(M=2.49)$ and visual $(M=2.61)$ impairments.

Principal component analysis of the short version of the attitude scale - A principal component analysis of the short version of the attitude scale with varimax rotation yielded three components (Table 3): benefits of inclusion (Component I), inclusive classroom management (Component II) and perspectives towards teaching students with specific types of disabilities (Component III). Component I consisted of items: 1, 2, 3, 4, 5, 6 and 11; Component II consisted of items: 7, 8, 9, 10 and 12; and Component III consisted of items: 13, 14, 15, 16, 17, 18 and 19. The items loaded on the first two components were consistent with those of Muwana (2012), who also modified the original scale in her study of Zambian student teachers' attitudes towards inclusive education. The reliability of the three components were: $\alpha=.78, \alpha=.65$ and $\alpha=.72$, with total mean scores of $M=3.95, M$ $=2.76$ and $M=3.17$, respectively. The components and their values, means and standard deviations are presented in (Table 3). 
Nketsia, W.

Table 3

Factor loading for principal component analysis with varimax rotation and Kaiser normalisation for attitudes scale and their mean scores and standard deviations

\begin{tabular}{|c|c|c|c|c|c|c|c|}
\hline & \multirow{2}{*}{ Statements } & \multicolumn{3}{|c|}{ Components } & \multirow{2}{*}{ Communalities } & \multirow{2}{*}{$M$} & \multirow{2}{*}{$S D$} \\
\hline & & $\mathrm{I}$ & II & III & & & \\
\hline 1 & $\begin{array}{l}\text { Students with disabilities/special needs should } \\
\text { be given every opportunity to function in the } \\
\text { general classroom where possible. }\end{array}$ & .80 & & & .96 & 4.22 & 0.96 \\
\hline 2 & $\begin{array}{l}\text { The inclusion of students with } \\
\text { disabilities/special needs can be beneficial for } \\
\text { students without disabilities. }\end{array}$ & .60 & & & .47 & 3.68 & 1.15 \\
\hline 3 & $\begin{array}{l}\text { Inclusion promotes social independence among } \\
\text { students with disabilities/special needs. }\end{array}$ & .66 & & & .57 & 3.88 & 1.06 \\
\hline 4 & $\begin{array}{l}\text { The nature of the study in general classrooms } \\
\text { will promote the academic growth of the } \\
\text { students with special needs/disabilities. }\end{array}$ & .54 & & & .39 & 3.69 & 1.15 \\
\hline 5 & $\begin{array}{l}\text { Inclusion promotes understanding and } \\
\text { acceptance of individual differences between } \\
\text { students without disabilities/special needs and } \\
\text { students with disabilities/special needs. }\end{array}$ & .57 & & & .41 & 4.03 & 0.95 \\
\hline 6 & $\begin{array}{l}\text { Inclusion promotes self-esteem among children } \\
\text { with disabilities/special needs. }\end{array}$ & .53 & & & .43 & 3.98 & 0.96 \\
\hline 11 & $\begin{array}{l}\text { Students with special needs can be best served } \\
\text { in general education classrooms. }\end{array}$ & .80 & & & .96 & 4.22 & 0.96 \\
\hline 7 & $\begin{array}{l}\text { Students with disabilities/special needs are } \\
\text { likely to create confusion in the general } \\
\text { education classroom. }\end{array}$ & & .61 & & .46 & 3.07 & 1.22 \\
\hline 8 & $\begin{array}{l}\text { It is likely that the students with special needs } \\
\text { will exhibit behaviour problems in a general } \\
\text { education classroom. }\end{array}$ & & .71 & & .49 & 2.63 & 1.10 \\
\hline 9 & $\begin{array}{l}\text { Increased freedom in the general classroom will } \\
\text { create too much confusion for the student with } \\
\text { disabilities/special needs. }\end{array}$ & & .66 & & .47 & 2.73 & 1.11 \\
\hline 10 & $\begin{array}{l}\text { The extra attention students with } \\
\text { disabilities/special needs require will be to the } \\
\text { detriment of the other students in the classroom. }\end{array}$ & & .54 & & .48 & 2.66 & 1.11 \\
\hline 12 & $\begin{array}{l}\text { It is difficult to maintain order in classrooms } \\
\text { that contain a mix of students with and without } \\
\text { disabilities/special needs. }\end{array}$ & & .65 & & .51 & 2.66 & 1.23 \\
\hline 13 & Visually impaired & & & .55 & .80 & 2.61 & 1.41 \\
\hline 14 & Hearing impaired & & & .66 & .76 & 2.49 & 1.22 \\
\hline 15 & Intellectually disabled & & & .70 & .51 & 3.03 & 1.23 \\
\hline 16 & Learning disabilities & & & .71 & .58 & 3.38 & 1.14 \\
\hline 17 & Physically disabled & & & .43 & .41 & 3.84 & 1.07 \\
\hline 18 & Behavioural problems & & & .59 & .55 & 3.56 & 1.14 \\
\hline 19 & Speech and language problems & & & .64 & .48 & 3.26 & 1.30 \\
\hline
\end{tabular}

Note. The total variance explained is $42.62 \%$.

Comparisons between the independent variables of Component I - The results from the comparative analysis indicate that men were more positive about the benefits of inclusion $(M=4.00)$ than women $(M=3.86)$, $t(482)=2.22, p=.03$. Those pre-service teachers who have had friends and classmates with disabilities were more positive about the benefits of inclusion $(M=4.02)$ than those who have not $(M=3.89), t(487)=-2.18, \mathrm{p}$ $=.03$. The mean scores also differed among the colleges: College $\mathrm{C}$ had the highest score $(M=4.08)$, followed by college $\mathrm{B}(M=3.92)$, while College A scored $(M=3.89)$ lower than College $\mathrm{C}$ according to post-hoc comparisons using the Tukey HSD test $F(2,492)=3.86, p=.02$. 
Comparisons between the independent variables of Component II - Pre-service teachers who had not completed the SEN course achieved higher mean scores for inclusive classroom management $(M=2.85)$ than those who had $(M=2.70) t(391.24)=-2.12, \mathrm{p}=.03$. The first-year participants achieved the highest mean score $(M=2.84)$, followed by those in the second year $(M=2.76)$. Post-hoc comparisons using the Tukey HSD test indicated that the third-year participants scored $(M=2.63)$ significantly lower than their first-year counterparts $F$ $(2,492)=3.00, p=.05$. Also, College B had the highest score $(M=2.88)$, followed by College $\mathrm{A}(M=2.76)$, and College $\mathrm{C}(M=2.65)$ differed significantly only from College $\mathrm{B}$, as indicated by post-hoc comparisons using the Tukey HSD $F(2,492)=3.09, p=.05$.

Comparisons between the independent variables of Component III - The results also indicate that those who had completed a SEN course $(M=3.27)$ showed more positive perspectives regarding teaching students with specific types of disabilities than those who had not $(M=3.00), t(478)=3.79, p=.00$. Moreover, those who have had friends and classmates with disabilities $(M=3.24)$ showed more positive perspectives regarding teaching students with specific types of disabilities than those who have not $(M=3.10), t(481)=-.2 .00, p=.05$. College $\mathrm{C}$ recorded the highest score $(M=3.38)$ while College A $(M=3.07)$ and College $\mathrm{B}(M=3.09)$ scored significantly lower than College $\mathrm{C}$ according to post-hoc comparisons using the Tukey HSD test $F(2,486)=$ $8.01, p=.00$. The second-year participants also scored the highest $(M=3.30)$, followed by those in the third year $(M=3.24)$. Post-hoc comparisons using the Tukey HSD test indicated that the mean score for the first-year participants $(M=3.01)$ was statistically different from those of the participants in their second and third years $F$ $(2,486)=7.50, p=.00$.

\section{Discussion}

The present study was designed to determine pre-service teachers' views and opinions regarding the religious/magical and cultural beliefs about disabilities, views about disability, level of discomfort interacting with people with disabilities, attitudes towards inclusive education as well as the effect of the background characteristics on these variables. Overall, the study found that pre-service teachers disagreed with religious/magical and cultural beliefs about disabilities. However, only about half of them disagreed with the beliefs that disability is caused by sorcery, witchcraft or the devil or that it is the result of an offence against God, gods or ancestral spirits. A quarter of them agreed and over a quarter of them was undecided about these beliefs. The results are consistent with other findings indicating that university students in Ghana (Naami \& Hayashi, 2012), most pre-service teachers in Botswana (Dart, 2006), teachers in United Arab Emirates (Gaad, 2004) and pre-service teachers in Bangladesh (Malak, 2013) are predisposed to misconceptions and superstitious beliefs about the causes of disability which influence them to worry about students with disabilities.

The study further found that the only background variable of the respondents that significantly impacted on agreement with religious/magical and cultural beliefs was the differences in the colleges of education: College $\mathrm{C}$ strongly agreed while College A demonstrated the least agreement. Surprisingly, no differences were found between those who had completed the SEN course and those who had not. This finding was unexpected and suggests that training in the SEN course was not significantly effective in repudiating religious/magical and cultural beliefs. The considerable number of pre-service teachers still predisposed to these beliefs might adopt attitudes and teaching practices that are hostile to the inclusion of students with disabilities and special needs in regular classrooms. Teacher education must adopt effective strategies to adequately address these negative, deep-rooted religious/magical and cultural beliefs, attitudes and prejudices and the barriers they might create.

Consistent with the findings of Kuyini and Mangope (2011), the results of the current study showed that pre-service teachers' attitudes were imperceptibly positive. Pre-service teachers held more positive attitudes about the benefits of the inclusive education component and were strongly positive about the inclusion of students with specific disability components. However, they were quite undecided about their inclusive classroom management skills. They were more positive about educating students with physical disabilities in general education classrooms but expressed the least positive attitudes towards the education of students with 
sensory, hearing and visual impairments. Similarly, studies from Zambia (Muwana, 2012), United Arab Emirates (Gaad, 2004; Nisreen, 2013) and Egypt (El-Ashry, 2009) reinforced that teachers support the inclusion of students with mild disabilities. However, inclusion for some and exclusion for others makes the concept of inclusion meaningless (Gaad, 2004).

Contrary to expectations, the pre-service teachers' attitudes towards inclusion differed only among the colleges of education, with College $\mathrm{C}$ holding more positive attitudes towards inclusive education. Previous studies from Botswana, Ghana, India, Bangladesh, Egypt, United Arab Emirates and Jordan have shown that other background variables promote positive attitudes towards inclusive education, for example; the completion of the special education course (Campbell et al., 2003; Dart, 2006; Kuyini \& Mangope, 2011; Sharma et al., 2008); closer contacts with persons with disabilities (Dart, 2006; Malak, 2013; Parasuram, 2006); educational programme specialisation (Alghazo et al., 2003; Haimour, 2012), advanced levels of education and the gender of pre-service teachers (EL-Ashry, 2009) and previous teaching experiences with children who have disabilities (Nisreen, 2013). These findings suggest that the SEN course needs to be improved in order to promote positive pre-service teacher attitudes towards inclusive education.

However, the three components within the attitudes scale yielded some significant differences between the independent variables. The results indicate that male pre-service teachers and those who have had close contact with people with disabilities were more positive about the benefits of the inclusive education component. The inclusion of students with specific disabilities in regular classrooms was viewed positively by those who had completed the SEN course, by the second- and third-year participants and by those who have had close contact with people with disabilities.

Despite the centralised nature of the curriculum within the colleges of education in Ghana, College $\mathrm{C}$ held more positive attitudes about the benefits of inclusive education and the perceptions regarding the inclusion of students with specific disabilities. College B held more positive attitudes regarding inclusive management skills. This finding suggests that, perhaps, some colleges are more effective at improving teachers' attitudes in some aspects than others.

Inclusive education is rooted in the social model view of disability and requires the removal of structural and attitudinal barriers and an adaptation of the existing regular education school system to meet the learning needs of all learners (UNESCO, 2009, 1994). This means that understanding disability from the social model perspective will promote the implementation of inclusive education. Generally, the pre-service teachers understood disability in terms of the WHO's biopsycho-social model of disability adopted in the current policy on inclusive education in Ghana (Ministry of Education, 2015). The conceptualisation of this model was higher among males and first- and second-year participants. However, the pre-service teachers' understanding of disability was significantly higher in terms of biological factors than environmental factors. The third-year pre-service teachers' understanding of disabilities in terms of environmental factors was higher than that of their first- and second-year counterparts. This could be due to their awareness of the school environmental factors in creating disabilities during teaching practice.

Another important finding was that, generally, pre-service teachers felt more comfortable interacting with people with disabilities. These results are inconsistent with those of Naami and Hayashi (2012), who found that university social work students felt uncomfortable interacting with persons with disabilities. Nevertheless, contrarily to findings of previous studies, no significant differences were found when all the independent variables were compared on comfort levels. Other studies have shown that meaningful contact with persons with disabilities (Carroll et al., 2003; Sharma, Forlin, \& Loreman, 2008) and taking a special education course (Campbell et al., 2003; Dart, 2006) explained changes in scores on comfort levels in a positive direction.

\section{Conclusions}

The results of this study have important implications for teacher preparation programs, school administrators, 

policy makers, teachers, and students with regards to the successful implementation of inclusive education policy in Ghana (see Ministry of Education, 2015) and other African, Asian and Middle East contexts with similar cultural beliefs about disabilities. The findings indicate that more needs to be done to address pre-service teachers' views and opinions regarding cultural beliefs about the causes of disability and special needs and attitudes towards inclusive education. The SEN course appears to be ineffective at expunging cultural beliefs about disability and barely promotes positive attitudes among pre-service teachers.

Studies must be carried out in these contexts to analyse the effects these cultural beliefs have on teachers' attitudes towards inclusive education. The understanding of the belief structures of teachers is an essential step to cultural and attitudinal change to improve teachers' professional preparation and teaching practice to ensure successful inclusion (Gaad, 2004; Schechtman \& Or, 1996). Schechtman and Or (1996) argued that radical methods of intervention is required to effectively deal with teachers' distorted beliefs and convictions about self and others. Their study from Israel showed that training programs could alter teachers' stereotypic thinking and prejudices regarding students with SEN. The initial teacher education programs in African, Asian and Middle East contexts should adopt well-planned intervention programs and practical measures to enable pre-service teachers to critically reflect on their beliefs and attitudes towards persons with disabilities.

The teacher training special education course should incorporate assignments that require pre-service teachers to reflect on their own practices, such as structured field experiences that increase pre-service teachers' contact with people with disabilities. These strategies have been found to be effective at increasing pre-service teachers' knowledge about disability, explaining positive changes in scores on comfort levels and improving their attitudes towards disability and inclusion. Also, more emphasis must be placed on inclusive instructional strategies and the social model understanding of disability in the special education course to prepare teachers to adapt the curricula and school practices to improve learners' access to meaningful learning. The policies on inclusive education must adopt the social model and human rights understanding of disability to improve educational opportunities for children with disabilities and the lives of disabled people. Also, school administrators and teachers should endeavour to model positive attitudes for students without disabilities and encourage learning relationship among students.

The present study successfully determined pre-service teachers' views and opinions on religious/magical and cultural beliefs regarding disabilities, level of discomfort in interacting with people with disabilities, their attitudes towards inclusive education, views on disability and the impact of the special education course on these factors. However, more research on this topic needs to be undertaken to determine the extent to which pre-service teachers conceptualise disability as a political, economic and human rights issue.

\section{References}

Agbenyega, J. (2007). Examining teachers' concerns and attitudes to inclusive education in Ghana. International Journal of Whole Schooling, 3, 41-56.

Agbenyega, J. (2003). The power of labelling discourse in the construction of disability in Ghana. Retrieved from http://www.aare.edu.au/03pap/agb03245.pdf

Alghazo, E. M., Dodeen, H., \& Algaryouti, I. A. (2003). Attitudes of pre-service teachers towards persons with disabilities: Predictions for the success of inclusion. College Student Journal, 37, 515-522.

Ametepee, L. K., \& Anastasiou, D. (2015). Special and inclusive education in Ghana: Status and progress, challenges and implication. International Journal of Educational Development, 41, 143-152. http://dx.doi.org/10.1016/j.ijedudev.2015.02.007

Anthony, J. (2011). Conceptualising disability in Ghana: Implications for EFA and inclusive education. International Journal of Inclusive Education, 15, 1073-1086. http://dx.doi.org/10.1080/13603116.2011.555062

Avoke, M. (2001). Some historical perspectives in the development of special education in Ghana. European Journal of Special Needs Education, 16, 29-40. http://dx.doi.org/10.1080/08856250150501789 
Nketsia, W.

Avoke, M. (2002). Models of disability in the labelling and attitudinal discourse in Ghana. Disability \& Society, 17, 769-777. http://dx.doi.org/10.1080/0968759022000039064

Avramidis, E., \& Norwich, B. (2002). Teachers' attitudes towards integration/inclusion: A review of the literature. European Journal of Special Needs Education, 17, 129-147. http://dx.doi.org/10.1080/08856250210129056

Botts, B. H., \& Owusu, N. A. (2013). The state of inclusive education in Ghana, West Africa. Preventing School Failure: Alternative Education for Children and Youth, 57, 135-143. http://dx.doi.org/10.1080/1045988X.2013.798776

Campbell, J., Gilmore, L., \& Cuskelly, M. (2003). Changing student teachers' attitudes towards disability and inclusion. Journal of Intellectual and Developmental Disability, 28, 369-379. http://dx.doi.org/10.1080/13668250310001616407

Carroll, A., Forlin, C., \& Jobling, A. (2003). The impact of teacher training in special education on the attitudes of Australian pre-service general educators towards people with disabilities. Teacher Education Quarterly, 30, 65-79.

Central Intelligence Agency. (2015). The world factbook: Africa-Ghana. Retrieved from https://www.cia.gov/library/publications/the-world-factbook/geos/gh.html

Chhabra, S., Srivastava, R., \& Srivastava, I. (2010). Inclusive education in Botswana: The perceptions of school teachers. Journal of Disability Policy Studies, 20, 219-228. http://dx.doi.org/10.1177/1044207309344690

Dart, G. (2006). 'My eyes went wide open' - An evaluation of the special needs education awareness course at Molepolole College of Education Botswana. British Journal of Special Education, 33, 130-138. http://dx.doi.org/10.1111/j.1467-8578.2006.00428.x

De Boer, A., Pijl, S. J., \& Minnaert, A. (2011). Regular primary schoolteachers' attitudes towards inclusive education: A review of the literature. International Journal of Inclusive Education, 15, 331-353. http://dx.doi.org/10.1080/13603110903030089

Dhungana, B. M. (2006). The lives of disabled women in Nepal: Vulnerability without support. Disability \& Society, 21, 133-146. http://dx.doi.org/10.1080/09687590500498051

EL-Ashry, F. R. (2009). General education pre-service teachers' attitudes toward inclusion in Egypt (Unpublished doctoral dissertation). University of Florida, Florida.

Florian, V., \& Katz, S. (1983). The impact of cultural, ethnic, and national variables on attitudes towards the disabled in Israel: A Review. International Journal of Intercultural Relations, 7, 167- 79. http://dx.doi.org/10.1016/0147-1767(83)90019-6

Forlin, C., \& Chambers, D. (2011). Teacher preparation for inclusive education: Increasing knowledge but raising concerns. Asia-Pacific Journal of Teacher Education, 39, 17-32. http://dx.doi.org/10.1080/1359866X.2010.540850

Forlin, C., Loreman, T., Sharma, U., \& Earle, C. (2009). Demographic differences in changing pre-service teachers' attitudes, sentiments and concerns about inclusive education. International Journal of Inclusive Education, 13, 195-209. http://dx.doi.org/10.1080/13603110701365356

Gaad, E. (2004). Cross-cultural perspectives on the effect of cultural attitudes towards inclusion for children with intellectual disabilities. International Journal of Inclusive Education, 8(3), 311-328. http://dx.doi.org/10.1080/1360311042000194645

Gething, L., \& Wheeler, B. (1992). The interaction with disabled persons scale: A new Australian instrument to measure attitudes towards people with disabilities. Australian Journal of Psychology, 44, 75-82. http://dx.doi.org/10.1080/00049539208260146

Ghana Education Service. (2004). The development of education. National report of Ghana: The basic education division. Accra: Government Publications.

Groce, N. E. (1999). Disability in cross-cultural perspective: Rethinking disability. Lancet, 354, $756-757$. http://dx.doi.org/10.1016/S0140-6736(99)06140-1

Haimour, A. I. (2012). Undergraduate universities student's attitudes toward disabled persons in Saudi Arabia. European Journal of Educational Studies, 4, 269-280. 
A cross-sectional study of pre-service teachers' views about disability and attitudes towards inclusive education

Hudson, F., Graham, S., \& Warner. M. (1979). Mainstreaming: An examination of the attitudes of regular classroom teachers. Learning Disability Quarterly, 2, 58-62. http://dx.doi.org/10.2307/1511026

Iacono, T., Tracy, J., Keating, J., \& Brown, T. (2009). The interaction with disabled persons scale: Revisiting its internal consistency and factor structure, and examining item-level properties. Research in Developmental Disabilities, 30, 1490-1501. http://dx.doi.org/10.1016/j.ridd.2009.07.010

Kassah, A. K., Kassah, B. L. L., \& Agbota, T. K. (2012). Abuse of disabled children in Ghana. Disability \& Society, 27, 689-701. http://dx.doi.org/10.1080/09687599.2012.673079

Kuyini, A. B., \& Mangope, B. (2011). Student teachers' attitudes and concerns about inclusive education in Ghana and Botswana. International Journal of Whole Schooling, 7, 1-18.

Lamptey, D., Villeneuve, M., Minnes, P., \& McColl, M. A. (2015). Republic of Ghana's policy on inclusive education and definitions of disability. Journal of Policy and Practice in Intellectual Disabilities, 12, 108-111. http://dx.doi.org/10.1111/jppi.12114

Lambe, J., \& Bones, R. (2006). Student teachers' perceptions about inclusive classroom teaching in Northern Ireland prior to teaching practice experience. European Journal of Special Needs Education, 21, 167-186. http://dx.doi.org/10.1080/08856250600600828

Lindsay, G. (2003). Inclusive education: A critical perspective. British Journal of Special Education, 30, 3-12. http://dx.doi.org/10.1111/1467-8527.00275

Malak, M. S. (2013). Inclusive education reform in Bangladesh: Pre-service teachers' responses to include students with special educational needs in regular classrooms. International Journal of Instruction, 6, 195-214.

McCray, E. D., \& McHatton, P. A. (2011). 'Less afraid to have them in my classroom': Understanding pre-service general educators' perceptions about inclusion. Teacher Education Quarterly, 135-155.

Miles, M. (2002). Disability in an Eastern Religious Context, Journal of Religion. Disability \& Health, 6(2-3), 53-76. http://dx.doi.org/10.1300/J095v06n02_08

Ministry of Education. (2015). Final inclusive education policy. Ministry of Education, Republic of Ghana.

Muwana, F. (2012). Zambian student teachers' attitudes toward including students with disabilities in general education classrooms (Unpublished doctoral dissertation). University of Illinois at Urbana-Champaign, Illinois.

Naami, A., \& Hayashi, R. (2012). Perceptions about disability among Ghanaian university students. Journal of Social Work in Disability \& Rehabilitation, 11, 100-111. http://dx.doi.org/10.1080/1536710X.2012.677616

National Advisory Board on Research Ethics in Finland. (2009). The ethical principles of research in the humanities and social and behavioral sciences and proposals for ethical review. Retrieved from http://www.tenk.fi/sites/tenk.fi/files/eettisetperiaatteet.pdf

Nisreen, A. (2013). The pros and cons of inclusive education from the perceptions of teachers in the United Arab Emirates. International Journal of Research Studies in Education, 2(1), 55 - 66.

Ocloo, M. A., \& Subbey, M. (2008). Perception of basic education school teachers towards inclusive education in the Hohoe District of Ghana. International Journal of Inclusive Education, 12, 639-650. http://dx.doi.org/10.1080/13603110802377680

Oliver, M. (2013). The social model of disability: Thirty years on. Disability \& Society, 28, 1024-1026. http://dx.doi.org/10.1080/09687599.2013.818773

Pacha, M. (2012). Education for tribal children: An engine for human Development. International Journal of Research Studies in Education, 1(1), 99-106.

Parasuram, K. (2006). Variables that affect teachers' attitudes towards disability and inclusive education in Mumbai, India. Disability \& Society, 21, 231-242. http://dx.doi.org/10.1080/09687590600617352

Schechtman, Z., \& Or, A. (1996). Applying counselling methods to challenge teacher beliefs with regard to classroom diversity and mainstreaming: an empirical study. Teaching and Teacher Education, 12(2), 137-47. http://dx.doi.org/10.1016/0742-051X(95)00027-H

Scruggs, T., \& Mastropieri, M. (1996). Teacher perceptions of mainstreaming/inclusion, 1958-1995: A research synthesis. Exceptional Children, 63, 59-74. 
Nketsia, W.

Sharma, U., Forlin, C., \& Loreman, T. (2008). Impact of training on pre-service teachers' attitudes and concerns about inclusive education and sentiments about persons with disabilities. Disability \& Society, 23, 773-785. http://dx.doi.org/10.1080/09687590802469271

Singal, N., Salifu, E. M., Iddrisu, K., Casely-Hayford, L., \& Lundebye, H. (2015). The impact of education in shaping lives: Reflections of young people with disabilities in Ghana. International Journal of Inclusive Education, 19, 908-925. http://dx.doi.org/10.1080/13603116.2015.1018343

Thomas, C. (2008). Disability: Getting it 'right'. Journal of Medical Ethics, 34, 1-17. http://dx.doi.org/10.1136/jme.2006.019943

United Nations. (2006). Convention on the rights of persons with disabilities and optional protocol. New York: Author. Retrieved from http://www.un.org/disabilities/default.asp?id=150

UNESCO. (1994). The Salamanca statement and framework for action on special needs education. Presented at the World Conference on Special Needs Education: Access and Quality. Salamanca: Spain.

UNESCO. (2009). Policy guidelines on inclusion in education. Paris: Author.

UNESCO. (1988). A case study of special education in Ghana. Accra: Ministry of Education. Retrieved from http://unesdoc.unesco.org/images/0009/000944/094448eb.pdf

UNESCO Institute for Statistics (UIS) \& UNICEF. (2015). Fixing the broken promise of education for all: Findings from the global initiative on out-of-school children. Montreal: UIS.

UNICEF. (2015). Youth with disabilities fact sheet. Retrieved from http://unsdn.org/youth-with-disabilities-fact-sheet/

UNICEF. (2013). State of the world's children 2013: Children with disabilities. New York: Author.

WHO. (2001). International classification of functioning, disability and health. Geneva: Author.

WHO \& World Bank. (2011). World report on disability. Geneva, Switzerland: Authors. 